\title{
Assessment of brainstem damage by the auditory brainstem response in acute severe head injury
}

\author{
TAKASHI TSUBOKAWA, HIROSHI NISHIMOTO, TAKAMITSU YAMAMOTO, \\ MORIHIKO KITAMURA, YOICHI KATAYAMA, AND NOBUO MORIYASU
}

From the Department of Neurological Surgery, Nihon University School of Medicine, Tokyo, Japan

SUMMARY In 64 cases suffering from severe head injury (Glasgow coma scale: less than seventhe auditory brainstem responses (FARs) recorded at the vertex, which are thought to be volumet conducted far-field potentials reflecting the sequential electrical activities of the auditory afferen) system in the brainstem, were recorded in the neurosurgical intensive care room immediately after admission. The alterations in the responses were compared with the types of primary injury, neurological signs, CT findings and outcome following treatment. Based on the results obtained, it is concluded that the FAR is a useful indicator for predicting the effects of treatment on brainstem damage in patients with severe head injury, and that it provides more reliable information about the function of the brainstem than the neurological signs or CT findings. Moreover, it also offers a diagnostic method for primary brainstem injury. Three cases or primary brainstem injury without lesions in the supratentorial region were diagnosed by means of combined CT and FAR recording.

The outcome of severe head injury depends largely on the damage to the brainstem, secondary or primary, and it is important to know the activity of the brainstem for successful management of patients with severe head injury in the acute stage. For this purpose, attempts have been made to use the caloric vestibulo-ocular response, ${ }^{1-4}$ orbicularis oculi reflex ${ }^{5}$ and various evoked potentials ${ }^{7}$ in addition to observations of the neurological signs. However, the results of such tests did not always correlate with brainstem function and did not predict the outcome of the cases; the various components of the responses were not related to specific neural structures and the physiological significance of the changes in amplitude of the responses was not clear.

The far-field acoustic response ${ }^{9}$ or auditory brainstem response (FAR) was first described by Jewett ${ }^{10}$ in 1970. The FAR has been shown by subsequent studies ${ }^{11-14}$ to have its origin in the auditory afferent system of the brainstem, to be conducted to the scalp by volume-conduction, not to be influenced by the brainstem reticular formation and to be quite unaffected by the

\footnotetext{
Address for reprint requests: Dr $T$ Tsubokawa, Department of Neurological Surgery, School of Medicine, Nihon University Itabashi-ku, Tokyo, Japan.
}

Accepted 20 June 1980 administration of anaesthetics and various other medications in usual therapeutic doses. ${ }^{15}$

The present study was undertaken to determine whether the FAR can provide useful information for the quantitative and qualitative evaluation of brainstem damage in patients with severe head injury. It also investigated whether primary brainstem injury can be diagnosed from FAR studies, although evidence from both clini$\mathrm{cal}^{48}$ and neuropathological materials ${ }^{11} 1920$ strongly supports the hypothesis that primary isolated brainstem injury following head trauma may not exist.

\section{Subjects and methods}

The FAR was recorded in 64 patients (42 adults and 22 children) with severe head injury, all of whom had disturbance of consciousness lasting for more than 24 hours after hospitalisation and of a severity scoring less than seven on the Glasgow coma scale. Fourteen cases were diagnosed as acute extradural haematoma, 24 as acute subdural haematoma, 12 as intracerebral haematoma and 14 as cerebral contusions or concussion based on both CT scanning and angiography.

The FAR was recorded monopolarly at the vertex with the reference electrode placed on the earlobe, in response to clicks. Individual responses were amplified (time constant: $0.03 \mathrm{~s}$, high frequency attenuation: $1 \mathrm{KHz}$ ), summated (analysis time: 
10-25 ms) 2000 times, and recorded on an X-Y recorder for subsequent analysis. The click was generated by an audiogenerator (DANA JAPAN DA-502A) as one cycle of a sine wave at $3 \mathrm{KHz}$, and was delivered to the subjects by means of headphones. Various intensities within the range of 50 to $100 \mathrm{~dB}$ SL were employed.

Repeated FAR recordings were performed in each case, beginning at the acute stage within three days of injury and continuing until recovery from unconsciousness or death. Whenever the FAR was recorded, examinations of the neurological signs, the adjunctive diagnosis tests including CT were carried out.

In normal adults, the FAR is composed of seven positive waves (Ist wave-VIIth wave) with latencies of $1 \cdot 52 \pm 0 \cdot 11 \mathrm{~ms}$ (Ist wave), $2 \cdot 69 \pm 0 \cdot 18 \mathrm{~ms}$ (IInd wave), $3 \cdot 79 \pm 0 \cdot 15 \mathrm{~ms}$ (IIIrd wave), $5 \cdot 00 \pm 1 \cdot 6 \mathrm{~ms}$ (IVth wave), and $5 \cdot 67 \pm 0 \cdot 20 \mathrm{~ms}$ (Vth wave), respectively. As reported previously, these positive waves are believed to have their origin in the following structures: Ist wave, acoustic nerve; IVth wave, lateral lemniscus and adjacent areas; Vth wave, around the inferior colliculi; VIth wave, subthalamic area ${ }^{9}$; and VIIth waves, auditory afferent system of the thalamus. ${ }^{914}$

Since the VIth and VIIth waves are susceptible to the influence of the middle latency component 21 and are inconstant and unstable the Ist to V:th waves have been investigated. We have considered as pathological both a prolongation in the latency and disappearance of each wave component apart from the VIth and VIIth waves. However, a reduction in the amplitude of each wave was not considered as pathological if the wave was traceable, since the IV, VI, and VIIth waves are less discernible. ${ }^{10} 13$

\section{Results}

\section{Analysis of the FAR}

Among the 64 cases suffering from severe head injury (less than seven on the Glasgow coma scale), 28 cases ( $44 \%$ ) showed no abnormality of the FAR. In the other 36 cases $(56 \%)$ the abnormalities of the FAR could be classified into two distinct types: one had marked pro-

Table 1 Alterations in the $F A R$ of patients with severe head injury (less than seven on the Glasgow scale) in the acute stage

\begin{tabular}{lll}
\hline \multicolumn{1}{c}{ FAR patterns } & Adults & Children \\
\hline Normal & 18 & 10 \\
$\begin{array}{l}\text { Prolongation of latency, disappearance of Vth } \\
\text { wave }\end{array}$ & 6 & 7 \\
Disappearance of Ist-Vth, IInd-Vth waves & 18 & 5 \\
Total & 42 & 22 \\
\hline
\end{tabular}

longation of the latency of the waves or disappearance solely of the Vth wave, and the other was characterised by the absence of the Ist through Vth waves or disappearance of all the waves except the Ist wave (table 1). Based on our experimental results ${ }^{22}$ and various other reports, ${ }^{121423}$ abnormalities of the former type indicated functional impairment of the brainstem within the midbrain, while those of the latter indicated that the function of the pons and medulla already was affected by the damage.

Among the cases suffering from acute extradural hematoma, nine cases $(65 \%)$ of 14 showed a normal FAR, two cases had prolongation of the latency or disappearance of the Vth wave, and the other three cases $(21 \%)$ showed no waves except the Ist in some cases.

Among 24 cases suffering from subdural hematoma with a score of less than seven on the Glasgow coma scale, 18 cases had an abnormal FAR, of whom seven showed prolongation of the latency or disappearance of the $V$ th wave and 11 showed disappearance of the Ist-Vth waves or of all these waves except the Ist. In the adult group, the incidence of disappearance of the Ist-Vth waves was higher than in the infant group, in spite of an almost identical incidence of abnormal FARs.

Five of 12 cases suffering from intracerebral haematoma showed an abnormal FAR, and the incidence of disappearance of the Ist-Vth waves in such cases was very high.

Among 14 cases suffering from cerebral contusions or concussion, eight cases (57\%) (both infants and adults) had an abnormal FAR (table 2).

Three cases who were thought clinically to have sustained concussion or contusions, were diagnosed as having primary brainstem injury since CT scanning did not reveal any abnormality or there were only small-scale high-density spots in the brainstem, together with disappearance of all waves in the FAR or of all waves except the Ist. Necropsy revealed no remarkable changes in the supratentorial tissue, but haemorrhage and contusions were observed in the brainstem (figs 1 and 2). It was found that recordings of the FAR in conjunction with $C T$ scanning could identify primary brainstem injury without lesions in the supratentorial part of the brain following head impact.

Among the other 61 cases not suffering from primary brainstem injury, 33 had an abnormal FAR. The FAR in 13 of these cases showed prolongation of the latency of the waves or disappearance of the Vth wave, and the other 20 
Table 2 Incidence of abnormalities of the FAR in relation to the main type of primary disease

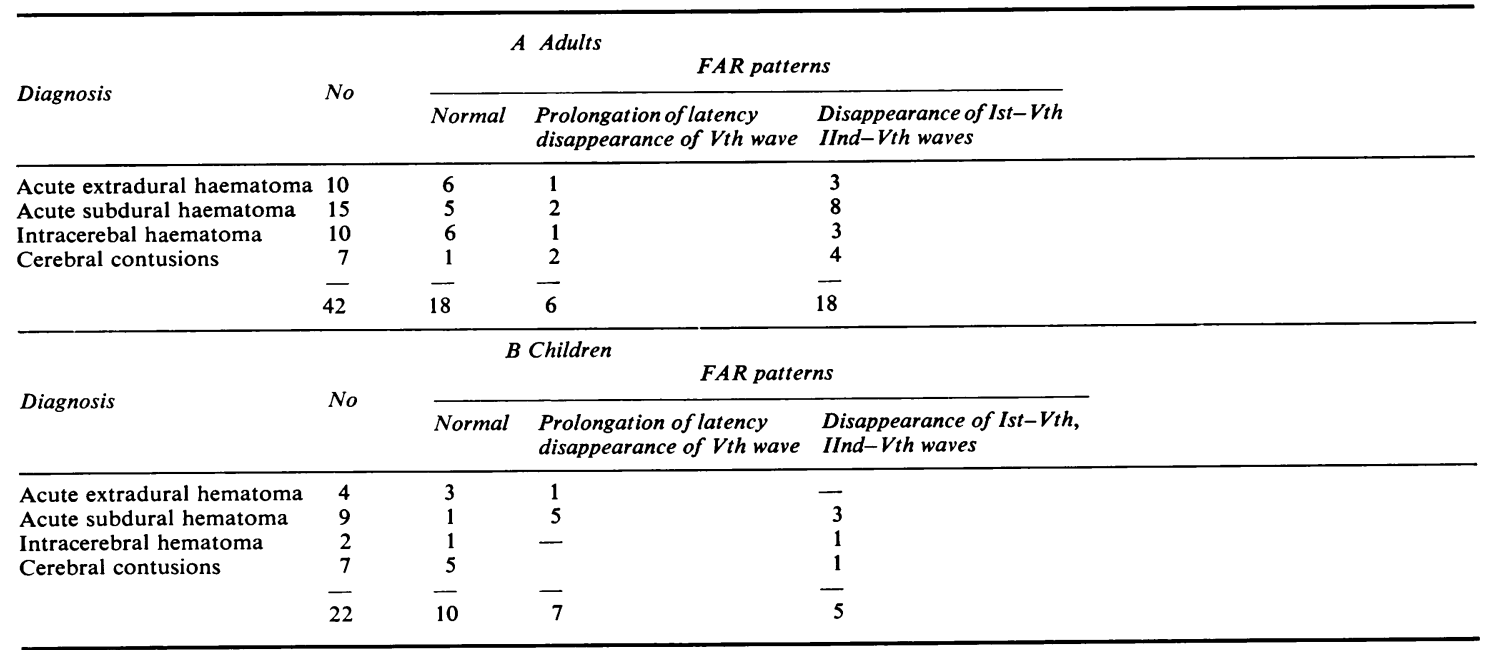

cases showed no response except in the Ist wave. tion following injury of the supratentorial brain The FAR abnormalities which indicated brain- tissue or intracranial hematoma. In order to stem damage represented a secondary dysfunc- determine whether the secondary brainstem tion caused by impending or complete hernia- damage occurred rostrocaudally the FAR was

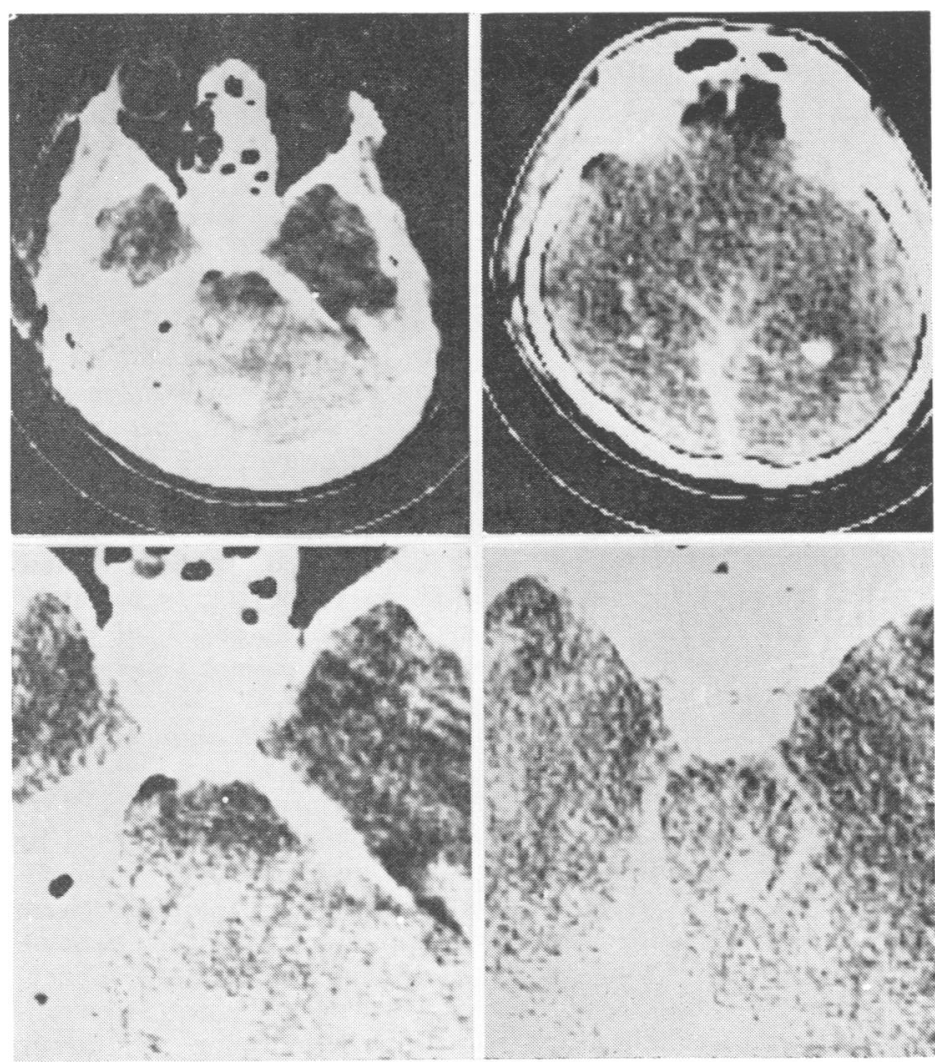

Fig 1 CT scans of primary brainstem damage caused by head injury. Note the several high-density spots in the brainstem. Upper: regular CT scan (EMI 1010). Lower: high accuracy and enlarged CT scan (EMI 10110). 

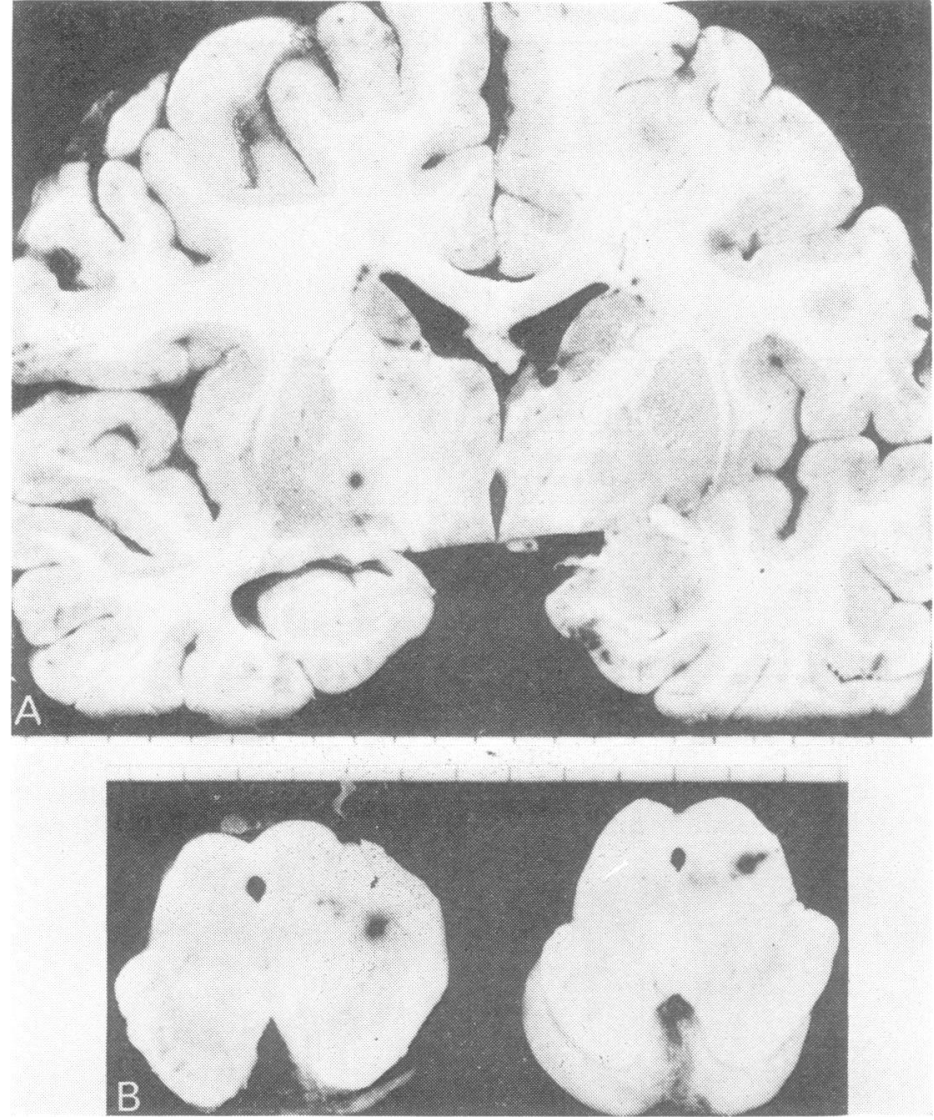

Fig 2 Necropsy findings at two months after injury. There is no marked damage in the supratentorial brain, but there is oedematous swelling with bleeding in the pericentral grey and tegmental area on the left side. A diagnosis of primary brainstem injury was established by $C T$ scanning and $F A R$ recording. recorded repeatedly in cases with FAR abnormalities. FAR abnormality consisting of prolongation of the latency or disappearance of the Vth wave, first recorded within 12-48 hours of injury could revert to a normal FAR within two to three weeks. However, in eight cases showing disappearance of the Vth wave in the FAR recorded at three to four hours after injury, the Vth, IVth, and IIIrd waves underwent stepwise disappearance and the FAR waves disappeared in repeated recordings at the terminal stages. Whenever the FAR showed only prolongation of the latency of the waves or disappearance of the Vth wave at 12-48 hours after injury, it was possible to predict that there would be a good outcome for survival. However, repeated FAR recording was necessary to demonstrate a step-wise disappearance of the Vth, IVth, and IIIrd waves so as to predict the ability to recover from brainstem damage, if the case shows prolongation of the latency of the waves recorded within 12 hours after injury. In cases showing disappearance of the Ist to Vth waves or IInd to Vth waves in the acute stage, the Ist and IInd waves reappeared over an ensuing period of more than 70 days, but recovery of the IIIrd, IVth, and Vth waves did not occur in any instance. Only six of the cases with such abnormalities eventually remained in a vegetative state: all the others died. Based on these results, it is possible to say that a survival of such cases showing disappearance of all waves or of all waves except the Ist cannot be expected.

\section{Relationship between FAR abnormalities and neurological signs}

The incidence of FAR abnormalities in relation to the presence of neurological signs caused by brainstem damage was assessed. The neurological signs caused by brainstem damage were classified into four stages based on the scheme of Plum and Posner, ${ }^{24}$ as follows: (1) diencephalic syndrome or IIIrd nerve palsy, (2) mesencephalic-upper pontine syndrome, (3) lower 
Table 3 Incidence of abnormalities of the FAR in relation to neurological signs associated with various levels of the brainstem

\begin{tabular}{|c|c|c|c|}
\hline \multirow{2}{*}{ Clinical signs } & \multicolumn{3}{|c|}{$F A R$ patterns } \\
\hline & Normal & $\begin{array}{l}\text { Prolongation of latency, } \\
\text { disappearance of Vth wave }\end{array}$ & $\begin{array}{l}\text { Disappearance of Ist-Vth } \\
\text { IInd-Vth waves }\end{array}$ \\
\hline $\begin{array}{l}\text { I Absence of brainstem dysfunction } \\
\text { II Presence of brainstem dysfunction } \\
\text { (1) diencephalic, IIIrd nerve } \\
\text { (2) mesencephalic-upper pontine } \\
\text { (3) lower pontine-upper medullary } \\
\text { (4) medullary }\end{array}$ & $\begin{array}{l}14(78 \%) \\
3(43 \%) \\
1(11 \%) \\
-\end{array}$ & $\begin{array}{l} \\
4(22 \%) \\
2(29 \%) \\
- \\
-\end{array}$ & $\begin{array}{l}2(29 \%) \\
8(89 \%) \\
7(100 \%) \\
1(100 \%)\end{array}$ \\
\hline \multicolumn{4}{|c|}{$F A R$ patterns } \\
\hline Clinical signs & Normal & $\begin{array}{l}\text { Prolongation of latency } \\
\text { disappearance of Vth wave }\end{array}$ & $\begin{array}{l}\text { Disappearance of Ist-Vth } \\
\text { IInd-Vth waves }\end{array}$ \\
\hline $\begin{array}{l}\text { I Absence of brainstem dysfunction } \\
\text { II Presence of brainsteam dysfunction } \\
\text { (1) diencephalic, IIIrd nerve } \\
\text { (2) mesencephalic-upper pontine } \\
\text { (3) lower pontine-upper medullary } \\
\text { (4) medullary }\end{array}$ & $\begin{array}{l}8(89 \%) \\
1(25 \%) \\
1(17 \%) \\
-\end{array}$ & $\begin{array}{l}1(11 \%) \\
2(50 \%) \\
4(67 \%) \\
-\end{array}$ & $\begin{array}{l}1(25 \%) \\
1(17 \%) \\
1(100 \%) \\
1(100 \%)\end{array}$ \\
\hline
\end{tabular}

pontine-upper medullary syndrome, and (4) medullary syndrome.

In the adult group, among 18 cases without neurological signs indicating brainstem dysfunction, 14 cases $(78 \%)$ had a normal FAR and four cases $(22 \%)$ showed prolongation of the latency or disappearance of the Vth wave. Among seven cases who had the diencephalic syndrome or IIIrd nerve palsy, a normal FAR was seen in three cases $(43 \%)$, prolongation of the latency or disappearance of the Vth wave in two cases $(29 \%)$ and disappearance of all waves or of all waves except the Ist wave in two cases (29\%). Among 17 cases with a mesencephalicupper pontine, lower pontine or medullary syndrome, all had lost the Ist-Vth waves, except one case with the mesencephalic syndrome (table 3). In cases having symptoms which suggested involvement extending from the midbrain to the upper portion of the pons, no waves of the FAR could be recorded in $89 \%$ of the cases in the adult group. In the infant group, however, FAR abnormalities consisting of disappearance of all the waves or of all the waves except the Ist were present in only $17 \%$ of cases with the same neurological signs as in the adult group. The FAR abnormalities in the infant group mostly consisted of prolongation of the latency of the waves or disappearance of the Vth wave; such abnormalities could recover. On the other hand, it should be noted that prolonged latency or disappearance of the Vth wave was observed in some cases without brainstem symptoms. This promised a good outcome, if adequate treatment was undertaken, indicating that FAR recording can sometimes provide an early diagnosis of brainstem dysfunction, even when neurological signs are not yet apparent.

\section{Relationship between FAR abnormalities and CT findings}

The status of the cisterns around the brainstem as visualised by $\mathrm{CT}$ scanning was classified into four grades (0-III) in terms of the onset of descending transtentorial herniation (DTH), based on the scheme of Stovring. ${ }^{25}$ Grade 0 was designated as normal, grade I was encroachment on the suprasellar cistern (impending herniation), grade II was widening of the crural ambient and lateral pontine cisterns or rotation of the brainstem (actual herniation), and grade III was effacement of the cisterns (advanced herniation). The relationship between the grading of DTH by CT scanning and alterations in the FAR was studied in 34 cases. In the normal group or those with impending tentorial herniation (grades O-I of DTH), nine cases $(90 \%)$ had a normal FAR and only one case had prolongation of the latency of the $V$ th wave. Among 12 cases belonging to grade II, which were herniating on Stovring's classification, ${ }^{25}$ five cases had a normal FAR, three had prolongation of the latency or disappearance of the Vth wave, and four had disappearance of the IstVth waves or IInd-Vth waves. Even in grade III, which represented advanced herniation on Stovring's classification, ${ }^{25}$ one case had a normal FAR, but the other 11 cases showed disappear- 
Table 4 Relationship between the grading of changes in the shape of the cisterns around the brainstem $^{24}$ and FAR abnormalities

\begin{tabular}{llll}
\hline & \multicolumn{4}{c}{ FAR patterns } \\
\cline { 2 - 4 } $\begin{array}{l}\text { DTH } \\
\text { grade }\end{array}$ & Normal & $\begin{array}{l}\text { Prolongation of latency } \\
\text { disappearance of Vth wave }\end{array}$ & $\begin{array}{l}\text { Disappearance of Ist- } \\
\text { Vth, IInd-Vth waves }\end{array}$ \\
\hline 0 & $1(50 \%)$ & $1(50 \%)$ & - \\
I & $8(100 \%)$ & - & - \\
II & $5(42 \%)$ & $3(25 \%)$ & $4(33 \%)$ \\
III & $1(8 \%)$ & - & $11(92 \%)$ \\
\hline Total & 15 & 4 & 15 \\
\hline
\end{tabular}

ance of the Ist-Vth waves or IInd-Vth waves (table 4).

Based on these results, alterations in the FAR appeared to be a more useful indicator of the brainstem damage, compared to the grading of descending tentorial herniation by CT scanning.

\section{Discussion}

The FAR $^{9}$ is composed only of the electrical activities of the auditory afferent system in the brainstem, and is conducted from the supratentorial brain tissue to the scalp by volumeconduction (far-field response). Accordingly, the FAR is unaffected by lesions in structures other than the brainstem, and now provide unique information about brainstem function. Clinical application of the FAR have been reported previously in relation to objective audiomentry, ${ }^{26}$ localising diagnosis of brainstem diseases ${ }^{1314}$ and judgement of brain death. ${ }^{12}$ Uziel et $a l^{23}$ have recently analysed the FAR in patients with coma due to various causes and claimed that coma can be classified into five stages according to the FAR findings.
In the present study, $56 \%$ of 64 head injury cases whose severity was less than seven on the Glasgow coma scale, showed FAR abnormalities, which could be divided into two groups: one had a prolonged latency or disappearance of the Vth wave suggesting damage to the midbrain, and the other was characterised by the absence of the Ist to Vth waves implying that the function of the pons and medulla was impaired. The former type of abnormalities tended to improve in the subsequent two to three weeks, and are thought to represent reversible changes (except in recording within 12 hours after injury); cases with such abnormality can expect a good outcome for life. In contrast, the latter type of abnormalities were ominous; the disappearance of the IIIrd to Vth waves was irreversible and the patients died or fell into a vegetative state.

The present observations indicate that use of the FAR can help early diagnosis of damage to the brainstem and can predict whether it is reversible or irreversible before the clinical symptoms become manifest. In contrast, CT findings obtained under such circumstances do not always reflect brainstem function. Among a variety of factors affecting the prognosis of severe head injury, irreversible damage of the brainstem must be considered as being of primary prognostic importance. Early detection of progressive brainstem damage is necessary for successful management, and intensive care must be carried out to prevent the establishment of irreversible brainstem damage. For this purpose, repeated recordings of the FAR are useful in providing a relevant early indicator of brainstem function for the treatment of severe head injury. Three cases of primary brainstem damage

Table 5 Relationship between the abnormalities of the FAR and the outcome of severe head injury in the adults and children

\begin{tabular}{|c|c|c|c|c|c|c|c|c|c|c|c|}
\hline$F A R$ & \multicolumn{2}{|c|}{$\begin{array}{l}\text { Good } \\
\text { recovery }\end{array}$} & \multicolumn{2}{|c|}{$\begin{array}{l}\text { A Adult } \\
\text { Moderate } \\
\text { disability }\end{array}$} & \multicolumn{2}{|c|}{$\begin{array}{l}\text { Severe } \\
\text { disability }\end{array}$} & \multicolumn{2}{|c|}{ Vegetative } & \multicolumn{2}{|c|}{ Dead } & Total \\
\hline $\begin{array}{l}\text { Normal } \\
\text { Prolongation of latency, disappearance of Vth wave } \\
\text { Disappearance of Jst-Vth, IInd-Vth waves }\end{array}$ & $\begin{array}{r}12 \\
4 \\
-\end{array}$ & $\begin{array}{l}67 \\
67 \\
-\end{array}$ & - & $\frac{28}{-}$ & $\frac{1}{-}$ & $\frac{6}{-}$ & $\begin{array}{c}- \\
1 \\
4\end{array}$ & $\begin{array}{l}\overline{17} \\
22\end{array}$ & $\begin{array}{r}-1 \\
14\end{array}$ & $\overline{17}$ & $\begin{array}{r}18 \\
6 \\
18\end{array}$ \\
\hline \multirow[b]{2}{*}{$F A R$} & \multicolumn{2}{|c|}{$\begin{array}{l}\text { Good } \\
\text { recovery }\end{array}$} & \multicolumn{2}{|c|}{$\begin{array}{l}\text { B Child } \\
\text { Moderate } \\
\text { disability }\end{array}$} & \multicolumn{2}{|c|}{$\begin{array}{l}\text { Severe } \\
\text { disability }\end{array}$} & \multicolumn{2}{|c|}{ Vegetative } & \multicolumn{2}{|c|}{ Dead } & \\
\hline & No & $\%$ & No & $\%$ & No & $\%$ & No & $\%$ & No & $\%$ & \\
\hline $\begin{array}{l}\text { Normal } \\
\text { Prolongation of latency, disappearance of } 5 \text { th wave } \\
\text { Disappearance of Ist-Vth, Ind-Vth waves }\end{array}$ & $\begin{array}{r}6 \\
2 \\
-\end{array}$ & $\begin{array}{l}60 \\
29 \\
-\end{array}$ & $\begin{array}{r}2 \\
2 \\
-\end{array}$ & $\begin{array}{l}20 \\
29 \\
-\end{array}$ & $\begin{array}{r}2 \\
2 \\
-\end{array}$ & $\begin{array}{l}20 \\
29 \\
-\end{array}$ & - & $\begin{array}{r}-1 \\
20\end{array}$ & $\begin{array}{r}-1 \\
4\end{array}$ & $\begin{array}{l}-\overline{14} \\
80\end{array}$ & $\begin{array}{r}10 \\
7 \\
5\end{array}$ \\
\hline
\end{tabular}


without lesions of the supratentorial region were diagnosed by combined FAR recording and CT scanning, although primary brainstem injury following head trauma may not exist alone. ${ }^{24811} 1827$ In our three cases, there was no abnormality in the supratentorial compartment; low density with small high-density spots in the brainstem or no abnormality even in the posterior fossa on the CT scans, together with disappearance of FAR waves, were present. These results closely resembled those in experimental fatal-concussion produced by high speed linear acceleration impact in monkeys. ${ }^{22}$

\section{References}

1 Blegvad B, Denmark C. Caloric vestibular reaction in unconscious patients. Arch Otolaryng 1962; 75:36.

2 Minderhoud JM, Van Woerkom Th CAM, Van Weerden TW. On the nature of brainstem disorders in severe head injured patients. II. A study on caloric vestibular reactions and neurotransmitter treatment. Acta Neurochir 1976; 34:23-35.

3 Poulsen J, Zilstorff K. Prognostic value of the caloric vestibular test in the unconscious patients with cranial trauma. Acta Neurol Scand 1972; 48:282.

4 Tomlinson BE. Brainstem lesions after head injury. Lancet $1970 ; 2: 443-8$.

5 Kimura J, McCormick WF. Orbicularis oculi reflex in coma. Clinical electrophysiological correlations. J Neurol Neurosurg Psychiatry 1972; 35:582-8.

6 Serrats AF, Parker SA, Merino-Canas A. The blink reflex in coma and after recovery from coma. Acta Neurochir 1976; 34:79-97.

7 Greenberg RP, Mayer DJ, Becker DP et al. Evaluation of brain function in severe human head trauma with multimodality evoked potentials. Part 1: Evoked brain-injury potentials, methods and analysis. J Neurosurg 1977; 47: $150-62$.

8 Greenberg RP, Mayer DJ, Becker DP et al. Evaluation of brain function in severe human head trauma with multimodality evoked potentials. Part 2: Localisation of brain dysfunction and correlation with post traumatic neurological conditions. J Neurosurg 1977; 47:163-77.

9 Tsubokawa T, Nishimoto H, Moriyasu N. Farfield responses of acoustic brainstem potentials in the thalamus and the subthalamic area. Neurol Medico-chir 1978; 18:1-4.

10 Jewett DL. Volume-conducted potentials in response to auditory stimuli as detected by averaging in the cat. Electroencephalogr Clin
Neurophysiol 1970; 28:609-18.

11 Crompton MR. Brainstem lesions due to closed head injury. Lancet $1971 ; 1: 669-73$.

12 Starr A. Auditory brainstem responses in brain death. Brain 1976; 99:543-54.

13 Starr A, Hamilton AE. Correlation between confirmed sites of far-field auditory brainstem responses. Electroencephalogr Clin Neurophysiol 1976; 41:595-608.

14 Stockard JJ, Rossiter VS. Clinical and pathologic correlates of brainstem auditory response abnormalities. Neurology 1977; 27:316-25.

15 Stockard JJ, Stockard JE, Sharbrough FW. Nonpathologic factors influencing brainstem auditory evoked potentials. Am J EEG Technol 1978; 18: 177-209.

16 Busch EAV. Brainstem contusions: differential diagnosis, therapy and prognosis. Clin Neurosurg 1961; 9:18-33.

17 Mitchell LE et al. Primary focal impact damage to the brainstem in blunt head injuries. Lancet $1973 ; 4: 215-8$.

18 Turazzi S, Alexandre $\mathrm{A}$, Bricolo $\mathrm{A}$. Incidence and significance of clinical signs of brainstem traumatic lesions. J Neurosurg Sci 1975; 19: 215-22.

19 Adams JH, Mitchell DE, Graham DI et al. Diffuse brain damage of immediate impact type. Its relationship to "primary brain-stem damage" in head injury. Brain 1977; 100:489-502.

20 Strich SJ. Shearing of nerve fibres as a cause of brain damage due to head injury. Lancet 1961; 2:443-8.

21 Picton TW, Hillyard SA, Krausz HI et al. Human auditory evoked potentials. I: Evaluation of components. Electroencephalogr Clin Neurophysiol 1974; 36:179-90.

22 Tsubokawa T, Nakamura S, Hayashi $\mathbf{N}$ et al. Experimental primary fatal head injury caused by linear acceleration. Neurol Medico-chir 1975; 15:57-65.

23 Uziel A, Benezech J. Auditory brain-stem responses in comatose patients. Relationship with brain-stem reflexes and level of coma. Electroencephalogr Clin Neurophysiol 1978; 45:515-24.

24 Plum F, Posner JB. The diagnosis of stupor and coma. Second edition. Philadelphia: FA Davis, 1972.

25 Stovring J. Descending tentorial herniation: Findings on computed tomography. Neuroradiology 1977; 14:101-5.

26 Davis H. Principles of electric response audiometry. Ann Oto Rhino Laryng 1976; 28: supplement 85, 4-89.

27 Teasdale G, Jennett B. Assessment of coma and impaired consciousness. A practical scale. Lancet 1974; 2:81-3. 